With regard to the more southerly parts of Eastern Africa, and more especially the region between the Mozambique coast and Lake Nyassa, our knowledge has lately increased by leaps and bounds. The increase has been principally due to the systematic explorations of Mr. Consul O'Neill. 'The general remark may be permitted that, thanks chiefly to $\mathrm{Mr}$. O'Neill, we now have for the first time a fairly satisfactory knowledge of a region varied in its physical configuration, well watered, and fertile, which has hitherto remained a blank on our maps, notwithstanding the occupation of the coast by the Portuguese for nearly four centuries.

M. Giraud has returned this spring from his exploration of Lake Bangweolo and its outlet, and his unsuccessful attempt to cross Africa by way of the Upper-Congo; Mr. Arnot has crossed from Natal to the Bihé plateau by way of the Upper Zambesi Mr. Montagu Kerr has crossed Matabele-land and the Zambesi, and penetrated by a new route to the sonth-western shore of Lake Nyassa; and Mr. Richards has reached from Inhambane the southern districts of Umzila's kingdom. In Western Africa further additons have been made to our knowledge of the Congo, chiefly by the publication of Mr. Stanley's long-expected book and the map. which accompany it, and by Messrs. Grenfell and Comber's careful survey of the middle course of the Congo and the Bochini tributary to the junction of the great river Kwango.

The members of the French Expedition on the Ogowé and the northern tributaries of the Congo have also been doing good work in the survey of the territories newly acquired by France.

In South America a striking feat of exploration has been accomplished since my last address; the supposed inaccessible summit of Mount Roraima, on the confines of British Guiana and Brazil, was reached in December last by Mr. im Thurn and his companion, Mr. Perkins, accompanied by a small party of Indians.

In conclusion Lord Aberdare gave the following brief summary of the Admiralty surveys of the year 1884, for which he was indebted to the hydrographer, Capt. Wharton, R.N.: The continuous prosecutions of marine surveys in different quarters of the globe has been well maintained during the past year. The two home-surveying vessels have been employed, one on the west and the other on the east coast of Great Britain. On foreign surveys 60 officers and 500 men have been employed in four steam ships of war and five other smaller vessels. These ships have been at work in Newfoundland, the Bahama Islands, Magellan Straits, South Africa, Red Sea, Malay Peninsula, coasts of China and Korea, north-west coast of Australia, and amongst the Pacific islands. The most important additions to our hydrographical knowledge are as follows:- The survey of the Little Bahama Bank -will be shortly finished, and the same may be said of the southern shore of Newfoundland. The survey of the main strait of Magellan, to which reference was made in the last address, was completed early in the year. Many useful additions have been made to ports and salient parts of the coast of south-east Africa. In the Red Sea the intricate approaches to Sawakin have been well laid down. On the west coast of the Malay Peninsula, Penang harbour has been re-surveyed and the positions of the islands lying to the north-west and forming the eastern boundary of the ordinary route of vessels to Malacca Strait have been accurately determined. The unknown western shores of Korea, south of the approach to Seoul, for two degrees of latitude have been explored, and the main features of this island-studded shore laid down. New rivers and harbours have been entered, notably, the large river Yeun-san-gang, at the entrance to which stands the considerable town of Mokfo. There appears, however, to be little chance of immediate trade with Korea, in consequence of the absence of any valuable products and the scanty needs of the population. The southern approach to Haitan Strait on the Chinese coast, much used by British trade, has been re-charted. On the difficult shores of Western Australia such progress has been made as the small means at the disposal of the surveyors has permitted. In the Solomon Islands the Bougainville Strait has been charted. This Channel will in the future be most probably a highway for traffic between Eastern Australia and Japan. Many additions have been also made to the charts of various groups of other Pacific islands. The survey of the coasts of India carried on by officers of the Royal Navy and India Marine has been actively progressing. Surveys of Rangoon, Cheduba, and other ports in the Bay of Bengal, as well as harbours on the west coast of Hindostan, have been made. A re-survey of the great Canadian lakes has been com- menced in Georgian Bay, where trade by water is on the increase.

Lord Aberdare then intimated his resignation of the Presidency of the Society, the Marquis of Lorne having been elected to succeed him.

\section{PROF. REYNOLDS ON THE STEAM INDICATOR ${ }^{1}$}

THE object of this paper was to define the causes and extent of the disturbances in indicator diagrams. The theory, as given, had been taught for several years in Owens College; but the publication had been deferred to enable an extensive series of experiments to be made. These experiment; had now been carried out by Mr. A. W. Brightmore, stud. Inst. C.E., late Berkeley Fellow in Owens College. In the first place it was shown that there were five principal causes of disturbance, namely: the inertia of the piston of the indicator and its attached weights; the friction of the pencil on the paper, and its attached mechanism; varying action of the spring ; inertia of the drum; friction of the drum.

The effect of the inertia of the pencil and its attached mechan ism presented a mathematical problem, by the solution of which it was shown that there were two disturbances from this cause: one, a general enlargement of the mean indicated pressure, depending on the weight of the moving parts of the indicator, the stiffness of the spring, and the square of the speed. The other disturbance was a vibration of the pencil. Every indicator piston vibrated when disturbed, so that the period of vibration depended on the stiffness of the spring.

The error which these oscillations caused in the area of the diagram depended on their magnitude, and, to a greater extent, on the smailness of the number in a revolution. But the evil of these oscillations was not so much an effect on the area as in the disfigurement and the confusion they produced in the diagram. So long as there were thirty of these oscillations in a cycle, the necessary fluid friction of the indicator piston would so far reduce them as to render a fair diagram possible, but when the number was as low as ten it was all the pencil could do to prevent them upsetting the diagram.

The friction arising from the pressure of the pencil always acted to oppose the motion of the pencil, and therefore rendered it too large during expansion and exhaust and too small during compression and admission, and thus the general effect was to increase the size of the diagram. This friction consisted of that of the pencil on the paper; and that of the mechanism, caused by sustaining the pressure of the pencil. The effect of the friction of the pencil was greatly reduced by the motion of the paper. The magnitude of these effects taken together on the area of the diagram depended on the construction of the instrument and on pencil-pressure. From numerous experiments it would appear possible to make a clifference of as much as five per cent. in a locomotive in mid-gear by pencil-friction.

The couclusions, as regarded the motion of the pencil, were that the general effect of inertia and friction were both to increase the size of the diagram; that so long as the speeds were such that the number of vibrations of the pencil during a revolution of the engine was not greater than fifteen, the effect of inertia was less than one per cent., but that, if the number was greater than thirty, oscillations would show themselves unless the pencil-friction was increased. They might, by this, be kept down till the number of vibrations was equal to fifteen, but not farther, and then the necessary friction would affect the area of the diagram about five per cent. For the diagrams to be sensibly accurate, and free from oscillation, the speeds must not be greater than would make the number of vibrations equal to thirty. These speeds were given in the paper for Richards' indicators.

The effect of the inertia of the drum with an elastic cord was shown to be a nearly uniform elongation of the diagram. The result of the varying stiffness of the drum spring was a nearly uniform contraction. With Richards' indicator these two latter disturbances neutralized each other at a speed of $15^{\circ}$ revolutions per minute. Ai other speeds the effects were apparent in the length of the diagram ; but, except when the expansion was great and the connecting rod short, they did not affect the indicated pressure. The friction of the drum with an elastic cord caused the cord to be longer during the forward stroke than during the

"A Paper read at the Institution of Civil Engineers, May r9, "On the Osborne Reynolds F.R.S. 
backward stroke, so that the diagram was di-torted and shortened, the drum being uniformly behind its proper position during the forward stroke, and before its position during the backward stroke. This distortion diminished the area of the diagram according to the rate of expansion and the length and elasticity of the cord ased. This was definitely expressed by a formula. This disturbance, the influence of which was very great in cases of high expansion, large engines, and ordinary cords, appeared to have been unnoticed. The circumstances on which it depended were the elasticity of the cord and the friction of the drum, and the question was how far these existed in the ordinary indicators. It might be said that the diagrams which led to the discovery of this effect were taken with an indicator which had been in constant use for several years. It was in apparently perfect condition, and the diagrams did not differ essentially from those which had been previously taken. The cord was one which had been sup slied by the maker. The manner of the discovery was described: For years the autbor had pursued in the cla $s$ the method of testing the vibrations of the indicator pencil by projecting them on to the crank-circle, and he had noticed that the first oscillation fell short, and shorter in the back diagram than in the front. The cause of this was not obvious, and it was partly with a view to determine this cause that Mr. Brightmore's investigation was commenced. A slight error in the reducing rod, which had a fixed centre and a slot in which a stud in the slide-block worked, was altered. This, however, did not get rid of the effect. A new cord was substituted for the old one, and the effect was found to be much enhanced, the new cord being more elastic than the old one. This reduced it to the stretching of the cord, but it was only after carefully working out the effect of the inertia of the drum, and it was seen this was to lengthen the first oscillation at the back end that the friction was examined. The indicator was taken to pieces, cleaned and oiled; then the effect wos much reduced. Several new wires and cords were used, and eventually steel wire was adopted as the best. The test supplied by the oscillations could only be applied to diagrams taken at high speeds, and the test furnished by the influence upon area was vague. What was wanted was an independent means of determining the simultaneous positions of the drum and the engine-piston. As the best method of meeting this, it was decided to arrange an electric circuit through the pencil to the drum, with sufficient electromotive force to prick the paper, making the engine-piston close this circuit at eleven definite equidistant points in the motion backwards and forwards. This was successfully carried out, and the stretching of the cord during the backward and forward strokes was definitely ascertained. Taking the smallest results obtained with a cord, it appeared from these experiments that the least difference of stretching was to make this difference in inches 5 per cent. of the length of the cord in feet. Examples of this effect in diminishing the mean indicated pressure were given. 'Thus, in a locomotive cutting off at one-quarter it was 8 per cent.; in a condensing engine having 3.5 feet stroke, cutting off at one-tenth, 20 per cent. ; and the same compounded, ro per cent.

These would seem to be the smallest results that could have occurred in ordinary practice. The conclusion, however, that hitherto the normal indicated power from engines had been from Io to 20 per cent. too small must wait for verification. Yet there were not wanting independent evidences of such an effect. In diagrams taken from engines at high speeds the admission line would not but for this effect be vertical. It would show a certain amount of detail, and the first oscillation would not have a sharp top. Noreover, it was commonly found that the expansion line, allowing for clearance, was above the true expansion line for the steam. This apparent rise in the curve of expansion was exactly what would result if the apparent cut-off was too early, and thi was the result of the effect that had been considered. The author had tried several diagrams, and found that after correction the expansion line came out very close to the true curve.

In making these comparisons the explanation of another feature of diagrams became apparent. When the two diagrams were traced on the same card, there was sometimes a want of symmetry about them, and in this case the cut-off was shorter on the back than on the front diagram. This the author attributed to the friction of the drum when the cord for the back diagram was longer than that for the front. When this was the case the relative lengths of the cord were about $I$ to $I \cdot 8$. These observations were illustrated in a diagram from "Richards" Indicator." To test this diagram a tracing was taken, and reversed so that the tront diagram was superimposed on the back. It was observed that the diagrams were of different lengths, and the difference was about the same as the difference in cut-off; that notwithstanding the apparent cut-off in the back diagram was to that in the front in the ratio of 2 to 3 , the expansion line of the back diagram was the same shape as that. in the front; and that if the diagrams were restored, supposing the lengths of the cords used to have been 5 feet and 9 feet, the diagrams became exactly similar, and, allowing 2 per cent. clearance, the expansion line came to be the true expansion line for that cut-off. The mean pressure was 14 per cent. larger than from the original diagram.

Such instances as these seemed to sufficiently establish a case against the blind faith which appeared to be at present placed in the accuracy of the indicator diagrams. But, in conclusion, the author stated that he should be very disappointed if anything in this investigation should have the effect of diminishing reliance on the indicator itself. He would have the instrument treated fairly, and instead of being the object of unthinking worship he would have it the object of careful study and experimental investigation, so that the limits of its wonderful perfection might be known exactly, and that reliance placed on it which sprang from knowledge.

\section{THE VISITATION OF THE ROYAL OBSERVATORY, GREENWICH}

THE visitation of the Royal Observatory took place on Saturday last, when, in spite of bad weather, there was a numerous attendance. The following extracts (condensed in some case $)$ from the Report of the Astronomer-Royal to the Board of Visitors indicate the work of the past year. It will be gratifying to all to knuw that a considerable increase in the optical power of the Observatory is in contemplation.

Transit-Circle.-A reversion-prism made by Messrs. Troughton and Simms has been used since last June in obse vations with the collimators as well as with the transit-circle to reverse the apparent direction of measurement or of motion, a movement towards the left (as in transits of south stars) being converted into a movement towa ds the right, or upwards, or downwards, according to the position of the plane of reflection of the reversion-prism. The collimation-observations show no sensible personality depending on the apparent direction of measurement ; it has, however, been considered well, in order to eliminate any possible effect of the kind, to take half the measures in each determination of collimation with the direction of movement of the wire reversed as regards right and left. In the transits the practice is to observe on each day two clock-stars and also circumpolar stars with the direction of motion reversed. A comparison of the results from the reversed and ordinary observations of clock-stars shows sensible differences in the case of some observers, who, however, have probably not yet settled down into a definite habit of observing stars which appear to move in the reverse direction.

In order to determine absolute personal equations in the observation of slow-moving as well as of quick-moving stars of various magnitudes (whether the motion be from right to left or the reverse) and of limbs of the sun, moon, or planets, the Astronomer Royal has arranged, in concert with Mr. Simms, a personal equation instrument to be used with the transit-circle. In this instrument, which is on the point of completion, and was seen at work on Saturday, a vertical plate with a circular aperture, 6 inches in diameter, to represent the sun or moon, and several small pinholes, to represent stars of different magnitudes, is placed in the focus of an object-glass of about 7 inches aperture and of about 50 feet focal length (which is attached to the dew-cap of the transit-circle, when horizontal and pointing north), and is carried smoothly by clockwork from east to west or west to east at a rate which may be varied at will from that of a very close circumpolar star to three or four times that of an equatorial star by an ingenious but simple mechanical contrivance devised by $\mathrm{Mr}$. Simms. The apertures in the vertical plate are illuminated by direct sunlight or moonlight reflected by a plane mirror towards the object-glass, and the times of transit of the artificial sun, moon, or stars, which are to be observed over the wires of the transit-circle, are also registered automatically on the chronograph by means of insulated platinum studs, corresponding to the artificial objects, which make contact with other studs, corresponding to the wires in the field of view of the transit-circle. 